\title{
Análisis de los efectos de la implementación de un software interactivo para la inclusión social de personas con discapacidad y su beneficio en niños del centro de atención múltiple (CAM)
}

\author{
Analysis of the effects of the implementation of an interactive software for the \\ social inclusion of people with disabilities and their benefit in children of the \\ multiple care center (CAM)
}

\author{
VÁSQUEZ-GAMBOA, Saira Antonieta†*, GARCÍA-ORTEGA, Irene y RODRÍGUEZ-RAMÍREZ, \\ Felipe
}

Tecnológico Nacional de México- Instituto Tecnológico de Tehuacán, México.

ID $1^{\text {er }}$ Autor: Saira Antonieta, Vásquez-Gamboa / ORC ID: 0000-0001-7031-0467, CVU CONACYT ID: 997110

ID $1^{\text {er }}$ Coautor: Irene, García-Ortega / ORC ID: 0000-0001-9638-7577, CVU CONACYT ID: 997104

ID $2^{\text {do }}$ Coautor: Felipe, Rodríguez-Ramírez / ORC ID: 0000-0002-1991-3390, CVU CONACYT ID: 899136

DOI: $10.35429 / J B E .2020 .11 .4 .1 .10$

Recibido 10 de Enero, 2020; Aceptado 30 de Junio, 2020

\begin{abstract}
Resumen
La inclusión social representa incorporar a la vida comunitaria a personas que conviven y se relacionan entre sí, independientemente de su origen, condición social o actividad. Categóricamente representa acercarlo a una vida digna, y que cuente con servicios básicos para un desarrollo personal y familiar apropiado y razonable, sin embargo, la inclusión social es la tendencia a posibilitar que personas en riesgo de pobreza o de exclusión social tengan la oportunidad de participar de manera plena en la vida social, y así puedan disfrutar de un nivel de vida adecuado. El objetivo del presente trabajo muestra el análisis de los efectos de la implementación de un software interactivo cuya intención fue integrar las tecnologías de la información y comunicación a las actividades de aprendizaje, logrando la autodeterminación y la plena integración de las personas con discapacidad. Basado en el modelo de valoración de habilidades adaptativas para personas con parálisis cerebral.
\end{abstract}

Discapacidad, inclusión social, Software interactivo

\begin{abstract}
Social inclusion represents incorporating into community life people who live and relate to each other, regardless of their origin, social condition or activity. It Categorically represents bringing it closer to a dignified life, and that it has basic services for appropriate and reasonable personal and family development, however, social inclusion is the tendency to enable people at risk of poverty or social exclusion to have the opportunity to participate fully in social life, and thus can enjoy an adequate standard of living. The objective of this work shows the analysis of the effects of the implementation of interactive software whose intention was to integrate information and communication technologies to learning activities, achieving self-determination and full integration of people with disabilities. Based on the adaptive skills assessment model for people with cerebral palsy.
\end{abstract}

Disability, Social inclusion, Interactive software

Citación: VÁSQUEZ-GAMBOA, Saira Antonieta, GARCÍA-ORTEGA, Irene y RODRÍGUEZ-RAMÍREZ, Felipe. Análisis de los efectos de la implementación de un software interactivo para la inclusión social de personas con discapacidad y su beneficio en niños del centro de atención múltiple (CAM). Revista de Educación Básica. 2020. 4-11:1-10.

\footnotetext{
*Correspondencia al Autor (Correo Electrónico: sc_svgam@ittehuacan.edu.mx)

$\dagger$ Investigador contribuyendo como primer autor.
} 


\section{Introducción}

Incluir a personas con discapacidad en actividades de la vida cotidiana mejora sus conceptos básicos como son: valores, actitudes, comportamientos y destrezas, excluyendo cualquier dificultad física y de comunicación. Por medio de un programa de trabajo que optimiza la valoración de la descripción de los pre-requisitos y habilidades adaptativas que posee o que ya adquirió el alumno o aquellas que esta por lograr, contribuyendo a una mejor participación en la sociedad.

Para el desarrollo del presente proyecto la participación de la tecnología de asistencia (TA) se puede utilizar para ayudar a que una persona con una discapacidad participe plenamente en las actividades de la vida diaria. La tecnología de asistencia puede ayudar a mejorar la independencia funcional y facilitar las tareas cotidianas mediante el uso de dispositivos que ayudan a una persona a viajar, comunicarse con los demás, aprender, trabajar y participar en actividades sociales y recreativas. Ejemplos de esta tecnología pueden ser desde cualquier objeto sencillo, como una lupa, hasta un dispositivo de alta tecnología, como un computador que habla y ayuda a alguien a comunicarse. También pueden ser sillas de ruedas, andaderas y escúteres (scooters) que ayudan a movilizarse y pueden ser utilizados por personas con discapacidades físicas. Los teléfonos inteligentes han expandido significativamente la disponibilidad de la tecnología de asistencia para las personas con dificultades de visión o audición, o que tengan problemas con la comunicación eficaz de sus pensamientos debido a limitaciones mentales o físicas (cdc.gov, 2017).

En el Instituto Tecnológico de Tehuacán se desarrolló un software interactivo, para favorecer la inclusión social y la equidad educativa, basado en el modelo de habilidades adaptativas para personas con parálisis cerebral y otras discapacidades mediante el modelo APAC, con la intención de incursionar a los alumnos al uso de las TIC, para mejorar el rendimiento académico por medio de actividades tecno-lúdicas. Como resultado del desarrollo del software se propone la implementación y análisis de los efectos que causa en el alumno.
Los resultados aportan de manera detallada la evaluación de los avances del alumno. El software consta de doce módulos sensopercepción, discriminación de formas, nociones temporo espaciales, lateralidad, memoria auditiva, memoria visual, prenuméricos, esquema corporal, lectura, cálculo y escritura favoreciendo el desarrollo de habilidades adaptativas.

La realización de esta investigación es importante ya que de esta manera se pueden proponer estrategias en beneficio de los alumnos con discapacidad en el Centro de Atención Múltiple Gabriela Brimmer brindándoles apoyo efectivo.

Beneficia también al Instituto Tecnológico de Tehuacán, en el logro de metas institucionales.

Por último, servirá como propuesta para implementar en otros Centros de Atención Múltiple y de esta manera contribuir con la sociedad.

Este artículo está integrado de las siguientes secciones:

- Planteamiento del problema: En este apartado se expone la problemática que da pie a la realización de la investigación, el objetivo general, y pregunta de investigación.

- Metodología: Sección que muestra el proceso y las técnicas que se llevará a cabo para la recolección de datos y las etapas de ejecución del desarrollo del proyecto con detalle y precisión.

- Desarrollo: En este apartado se presenta el software interactivo, como propuesta de apoyo al proceso de aprendizaje

- Resultados: En esta sección se presentan los resultados de la implementación del software interactivo explicando los beneficios del mismo y propuestas de mejora.

- Conclusiones: En este apartado se concentran los resultados de la investigación. 
- Sugerencias: En este apartado se sugieren las recomendaciones pertinentes

- Agradecimientos: En este apartado se presentan los agradecimientos a las diferentes instancias y personas que apoyaron la realización del proyecto de investigación.

- Referencias bibliográficas: En esta sección se enlistan cada una de las fuentes de información que se ha utilizado en apoyó esta investigación.

\section{Planteamiento del problema}

El Centro de Atención Múltiple Gabriela Brimmer (CAM) de Tehuacán, Puebla, es una escuela de educación especial que brinda atención escolarizada integral a niños, niñas y jóvenes con discapacidad múltiple o trastornos graves del desarrollo, condiciones que dificultan su ingreso en escuelas regulares. En el CAM, la práctica educativa se realiza bajo un método tradicional de enseñanza, sin embargo, la falta de material de apoyo hace este método tardado.

Para que los alumnos puedan adaptarse al entorno es importante el progreso a través del desarrollo de las habilidades adaptativas que consiste en mejorar las capacidades, conductas y destrezas de cada uno, involucrando varios actores a un trabajo colegiado como son: la institución o escuela, la comunidad, la familia y por supuesto el alumno, quién será el actor principal en el proceso enseñanza-aprendizaje.

Dentro de la institución el docente es un actor importante que proporciona las condiciones de enseñanza-aprendizaje a los alumnos, sin embargo, el contar con un grupo que no presenta las mismas características de discapacidad, es complicado y tardado ver el desempeño individual. Por lo tanto, el docente realiza y propone una planeación para cada uno de los diferentes casos que se presenten en su grupo, facilitando las condiciones de aprendizaje. como ritmos, estilos de aprendizaje $\mathrm{y}$ necesidades educativas especiales. No, dejando de lado uno de los puntos complejos que es el momento de la evaluación que por ser en dos momentos requiere de más tiempo para su aplicación y elaboración del formato de respuesta.
En la Tabla 1, Se presenta el formato de respuesta que se elabora de manera manual para evaluar las habilidades, donde el docente indica el nivel de dominio que muestra cada uno de los alumnos. Vaciando información en cada columna según corresponda: Lo logra, No lo logra o en proceso, de igual forma también se integra en el formato la columna de observaciones donde se hacen anotaciones relacionadas con el avance del alumno. Cabe mencionar que el docente emite un formato de cada uno de los 12 módulos, aunado a esto los resultados son vaciados en un gráfico independiente para tener una impresión visual de las habilidades que domina el alumno, lo que hace que el proceso sea tardado.

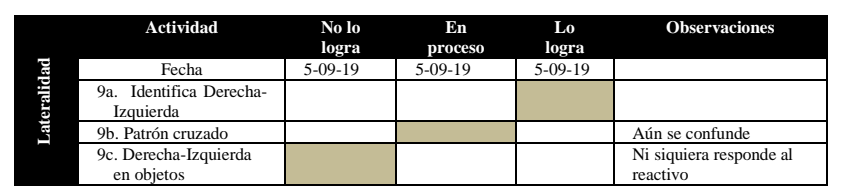

Tabla 1 Formato de respuesta funcionales

Fuente: (Mtra. Patricia Brogna, 2006)

Con la implementación del software interactivo se obtuvieron resultados satisfactorios, ya que las actividades que comprenden los doce módulos atendieron aspectos para favorecer la labor del docente en sus tres momentos didácticos del proceso de enseñanza aprendizaje planeación, ejecución y evaluación.

De tal manera, que se procedió a dar a conocer el software interactivo a la docente a cargo del grupo asignado presentando la propuesta para llevar a cabo la etapa de pruebas, y poder realizar el análisis de los efectos y beneficios de utilizar este nuevo proceso de enseñanza aprendizaje, así como también ofrece una manera más rápida para realizar la evaluación evitando tener que invertir más tiempo para su realización.

En la Figura 1 se muestra la presentación del proyecto a la docente encargada de participar en el proyecto. 


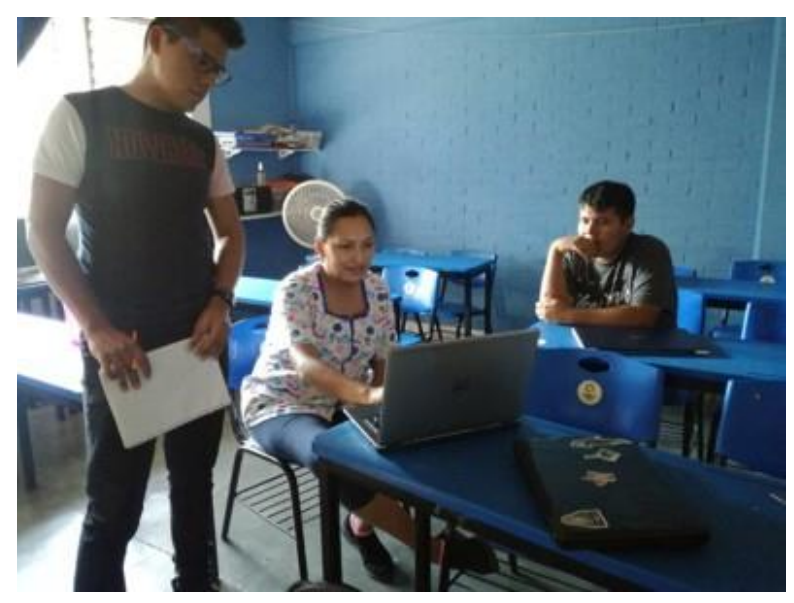

Figura 1 Presentación del software interactivo Fuente: Elaboración propia

\section{Objetivo general}

Analizar los efectos de implementar un software interactivo, para la inclusión social de personas con discapacidad, basado en el modelo de habilidades adaptativas para personas con parálisis cerebral y otras discapacidades mediante el modelo APAC y su beneficio en niños del Centro de Atención Múltiple Gabriela Brimmer de la ciudad de Tehuacán, Puebla.

\section{Pregunta de investigación}

¿Qué efecto produce el software interactivo en alumnos del Centro de Atención Múltiple CAM?

\section{Metodología}

La investigación se desarrolló bajo una metodología de tipo cualitativa que se encarga de recoger información basada en la observación y comportamientos naturales. Utilizando entrevistas, encuestas y observación siendo una Investigación-acción que sigue un modelo en espiral en ciclos sucesivos, compuestos por las fases de planificar, actuar, observar y reflexionar. Para la investigación se plantean tres ciclos, el primero consiste en proponer una mejora, siendo la primera parte que se llevó a cabo para determinar la realización del software interactivo que se encargó de automatizar las actividades del modelo de valoración de habilidades, en el Centro de Atención Múltiple Gabriela Brimmer CAM , el segundo ciclo tiene como finalidad implementar el software interactivo y evaluar los resultados de su implementación, el tercer ciclo tendrá como objetivo evaluar los efectos y beneficios de la implementación del software interactivo.

\section{Población y muestra}

El Centro de Atención Múltiple Gabriela Brimmer (CAM) proporciona servicio de educación especial teniendo la responsabilidad de inscribir alumnos y alumnas que presentan alguna discapacidad y que requieren de adecuaciones curriculares. Actualmente cuenta con 49 alumnos de los cuales 16 corresponden al sexo femenino y 33 al sexo masculino, que van de 2 a 20 años, atendiendo diferentes discapacidades como: trastornos del espectro autista (TEA), síndrome de DOWN, discapacidad motora (DM), discapacidad auditiva (DA), retraso psicomotor, demencia vascular (DV), trastorno generalizado del desarrollo (TGD), discapacidad intelectual (DI), inscritos en grupos como: inicial, preescolar, primaria y secundaria. Siendo los grupos de primaria y secundaria los beneficiados con el software interactivo para la inclusión social de personas con discapacidad DISCAP.

\section{Análisis}

La investigación del estudio consistió en analizar el modelo de valoración de habilidades, así como observar a los docentes de la institución para conocer la realización de sus actividades en cuanto a la planeación, ejecución y evaluación, para entender los procesos, conocer los requisitos de hardware y software y modelar cada uno de los módulos para que posteriormente se lleven a cabo en el software interactivo.

\section{Diseño}

Para la etapa de diseño se realizaron las siguientes actividades:

Diseñar los instrumentos de recolección de datos para conocer las necesidades de los docentes y conocer el modelo de valoración de las habilidades.

Aplicar los instrumentos y recolectar la información.

Actualizar requisitos funcionales y no funcionales.

Modelar la arquitectura del sistema y estructura de interfaces. 

software.

Programar y depurar módulos de

Evaluar software por docentes.

Realizar pruebas y correcciones de acuerdo con observaciones del docente.

Implementar el software interactivo.

Analizar y registrar los beneficios logrados en los niños del CAM con la aplicación del software interactivo.

\section{Desarrollo}

Para la aplicación de los instrumentos y análisis de la información, se solicitó autorización a la institución, iniciando con diferentes entrevistas realizadas a la docente encargada del proyecto, padres de familia y comunidad.

Posteriormente se asistió como observador a diferentes clases con los alumnos para conocer los aspectos relacionados al desarrollo de las habilidades de los doce módulos.

Antes de llevar a cabo esta actividad se entrevistó a padres de familia para solicitar su autorización y conocer su opinión acerca de introducir a sus hijos a las TIC.

También se encuesto a la comunidad cercana para dar a conocer la propuesta que se plantea a la institución con el objetivo apoyar a que los alumnos tengan un creativo e innovador proceso de enseñanza-aprendizaje.

Posteriormente se realizaron sesiones con la docente encargada de la información para verificar cada uno de los módulos y analizar las actividades, así como el contenido del módulo de evaluación que permitirá al docente tener las evaluaciones al inicio y final del ciclo escolar.

Como resultado de las etapas anteriores se obtuvo lo siguiente:
Un software interactivo que contempla doce módulos que permiten que el alumno desarrolle habilidades adaptativas, se contemplan las habilidades académicas funcionales, de comunicación, autocuidado, de vida en el hogar, autodirección, de uso de recursos de la comunidad, de ocio y tiempo libre, de trabajo, de salud y seguridad así como el módulo de evaluación, siendo este último un concentrado donde se evalúan las habilidades indicando tres tiempos de la evaluación a través de un semáforo así como las observaciones correspondientes.

El desarrollo e implementación del software interactivo es una propuesta que consiste en desarrollar actividades que apoyen la necesidad de un programa de trabajo, favoreciendo el desarrollo de las habilidades adaptativas a través de medios didácticos que facilitan información ofreciendo una mejor comunicación, de esta forma favoreciendo el aprendizaje a los estudiantes, quienes son orientados por los docentes tanto en los entornos de aprendizaje presencial como virtual.

La elección de los medios adecuados para cada situación educativa y el diseño de intervenciones educativas que consideren todos los elementos contextuales resultan ser factores clave para el logro de los objetivos educativos que se prueben.

Para el desarrollo del software interactivo se utilizó la metodología de prototipos porque permite que algunas de las partes del sistema final se construyan rápidamente para comprender bien su interacción y funcionalidad. Además, de ser una de las metodologías que mejor se adapta a la implementación de nuevos requerimientos o especificaciones según sea necesario, o de la forma que debería tomar la interacción humano-máquina (Bretón, García, \& Rojas, 2011).

El modelo de construcción de prototipos tiene tres pasos:

- Escuchar al cliente, recolectar requisitos, encontrar y definir los objetivos, se identifican los requisitos conocidos y las áreas donde es obligatorio más definición. 
- Construir y revisar la maqueta (prototipo).

- El cliente prueba la maqueta (prototipo) y lo utiliza para refinar los requisitos del software.

- Se realizaron pruebas de su funcionamiento con la docente encargada en el Centro de Atención Múltiple Gabriela Brimmer.

\section{Resultados}

El desarrollo del software interactivo como se ha descrito se realizó por módulos. Teniendo finalmente un software interactivo que puede ser utilizado por los docentes junto con los alumnos del Centro de Atención Múltiple Gabriela Brimmer.

En la Figura 2 se muestra la pantalla de inicio del software, donde se encuentra el logo de la Institución.

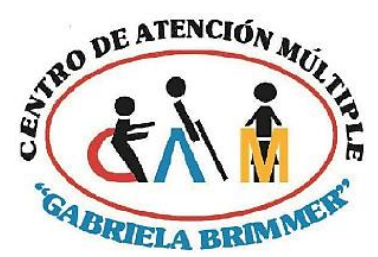

Figura 2 Pantalla de inicio del software interactivo Fuente: Elaboración propia

Posterior a la pantalla de inicio se muestran cada uno de los módulos con los que cuenta el software. En la Figura 3, se presentan los doce módulos de las habilidades académicas funcionales que permite al alumno ser partícipe de su propio proceso de desarrollo.

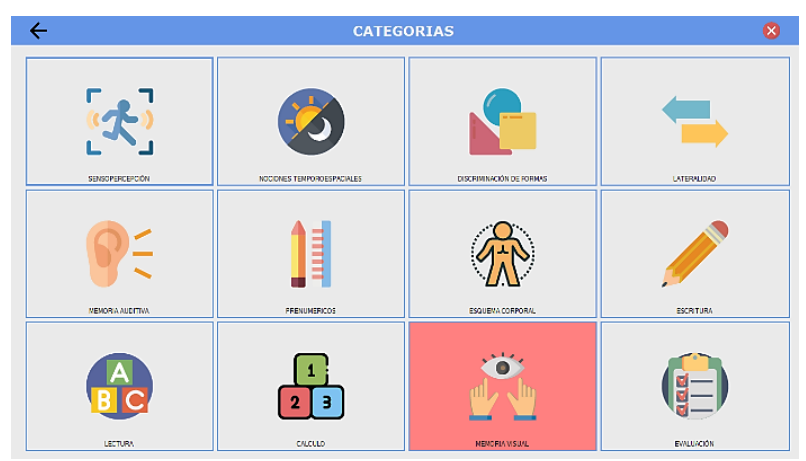

Figura 3 Módulo de las habilidades académicas funcionales

Fuente: Elaboración propia
En la Figura 4, se muestra la ventana correspondiente al módulo SENSOPERCEPCIÓN.

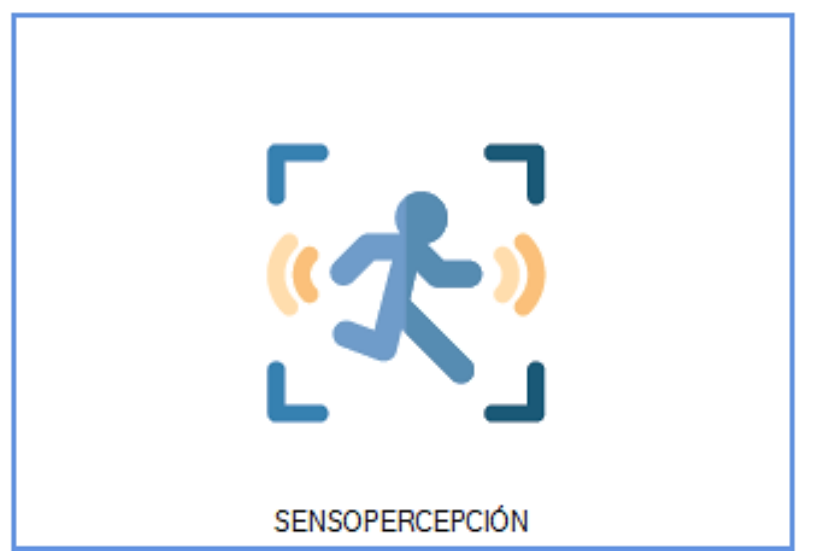

Figura 4 Módulo de SENSOPERCEPCIÓN

Fuente: Elaboración propia

Este módulo consiste en mostrar al alumno objetos (cubos, figuras geométricas, juguetes) o tarjetas de colores primarios, solicitándole que identifique el color azul, rojo y amarillo.

Por lo contrario, si por el tipo de discapacidad el alumno no pudiese hablar, se le solicita que señale el color indicado. Por otro lado, si el alumno, tiene problemas para realizar movimientos voluntarios se le indicará que mire el color solicitado por el docente.

En la Figura 5 se muestra el módulo de DISCRIMINACIÓN DE FORMAS geométricas básicas.

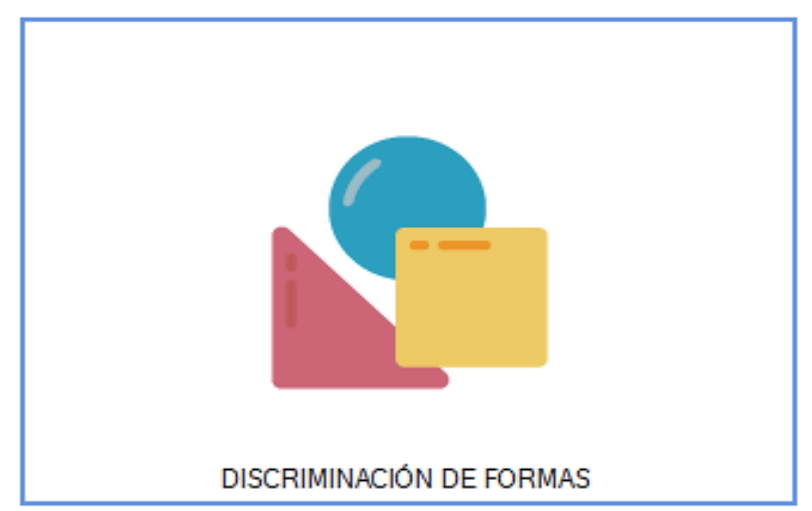

Figura 5 Módulo DISCRIMINACIÓN DE FORMAS

Fuente: Elaboración propia

En el caso de, la discriminación de formas se le solicita al alumno que mencione el nombre de la figura indicada, que la señale o reúna todas las figuras que son iguales. En caso de que el alumno no hable, se le pedirá que señale la figura indicada.

VÁSQUEZ-GAMBOA, Saira Antonieta, GARCÍA-ORTEGA, Irene y RODRÍGUEZ-RAMÍREZ, Felipe. Análisis de los efectos de la implementación de un software interactivo para la inclusión social de personas con discapacidad y su beneficio en niños del centro de atención múltiple (CAM). Revista de Educación Básica. 2020 
En la Figura 6 Se muestra el módulo NOCIONES TEMPOROESPACIALES que se utilizan para desarrollo de la psicomotricidad gruesa, fortalecer la destreza y disponer los elementos en el espacio, en el tiempo conjuntamente con actividades como caminar, correr, etc., que le permitirá al niño el control y coordinación de su cuerpo.

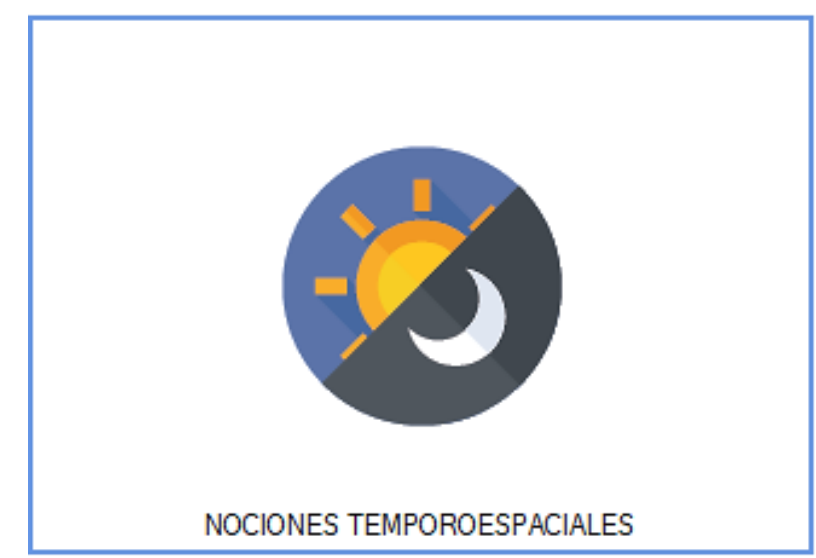

Figura 6 Módulo NOCIONES

TEMPOROESPACIALES

Fuente: Elaboración propia

Básicamente en este módulo se le muestra al alumno imágenes del día y la noche y se le solicita que diferencie, mientras el docente le realiza la pregunta de "¿En este dibujo es de ...", noche o de día? según sea el caso, así como también le muestra los días y le pregunta: ¿qué día es hoy?, ¿qué día fue ayer? y ¿qué día es mañana? para que señale el día indicado.

En caso de que el alumno no hable se le solicitará que con alguna parte de su cuerpo diga si o no. En la Figura 7 Se muestra el módulo de LATERALIDAD, que es la predilección que muestran la mayoría de las personas por un lado de su propio cuerpo.

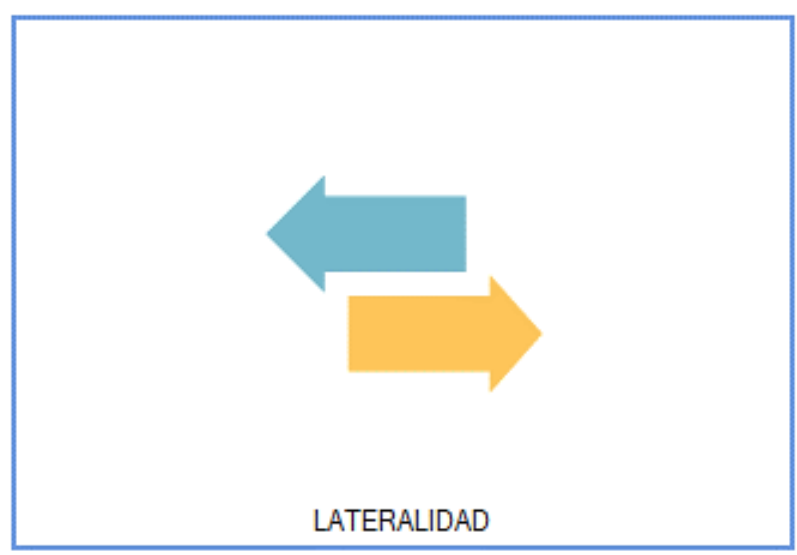

Figura 7 Muestra el módulo LATERALIDAD Fuente: Elaboración propia
Continuando con el módulo de LATERALIDAD, se presentan imágenes de mano derecha, mano izquierda y el docente solicita al alumno que muestre la mano derecha o izquierda. $\mathrm{Si}$ el alumno tiene alguna limitación física no le permiten mover de forma voluntaria la parte del cuerpo indicada, se le solicita que la señale con la vista.

En la Figura 8 Se muestra el módulo MEMORIA AUDITIVA, que se encarga de retener a corto plazo la información auditiva que se recibe del entorno.

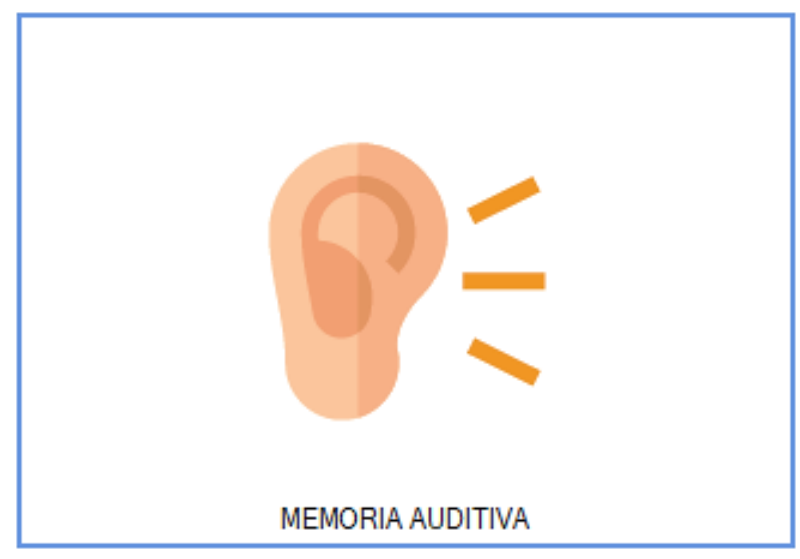

Figura 8 Módulo MEMORIA AUDITIVA

Fuente: Elaboración propia

De igual forma el módulo de MEMORIA AUDITIVA presenta imágenes de instrumentos que contienen audio, mostrando al alumno los sonidos y solicitando que los señale o mire. En la Figura 9 Se muestra la opción de PRENUMERICOS.

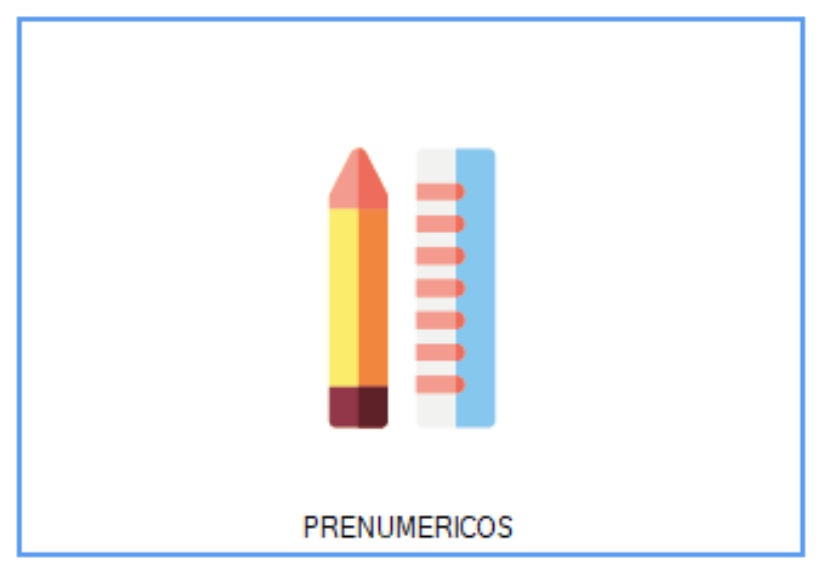

Figura 9 Módulo de PRENUMERICOS

Fuente: Elaboración propia

Igualmente, el menú de PRENUMERICOS muestra imágenes de objetos que le servirán al alumno para identificar, vacío-lleno, largo-corto, grandechico y clasifica.

VÁSQUEZ-GAMBOA, Saira Antonieta, GARCÍA-ORTEGA, Irene y RODRÍGUEZ-RAMÍREZ, Felipe. Análisis de los efectos de la implementación de un software interactivo para la inclusión social de personas con discapacidad y su beneficio en niños del centro de atención múltiple (CAM). Revista de Educación Básica. 2020 
Se presenta objetos concretos, como cuerdas, lápices de diferente longitud. Así como imágenes de recipiente lleno y uno vacío. Y se realiza la misma indicación de que señale o mire. En la Figura 10 Se muestra el módulo de ESQUEMA CORPORAL que indica que el alumno identifique partes finas orejas, nariz, codo, dientes, muñeca, tobillo, pestañas y cejas.

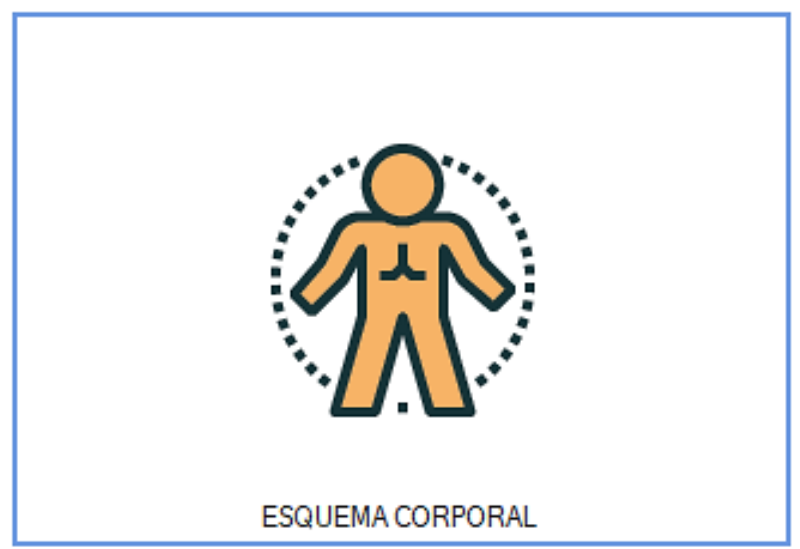

Figura 10 Módulo ESQUEMA CORPORAL Fuente: Elaboración propia

En este módulo, por medio de las imágenes se le solicita al alumno que señale y mencione las partes del cuerpo que se le indican. Cuando el alumno es muy limitado el docente le hará las preguntas al alumno y se concretará sólo a señalar en él las partes del cuerpo. En la Figura 11 Se muestra el módulo de ESCRITURA para reconocer vocales y consonantes, minúsculas, mayúsculas, escribe su nombre, lee sílabas.

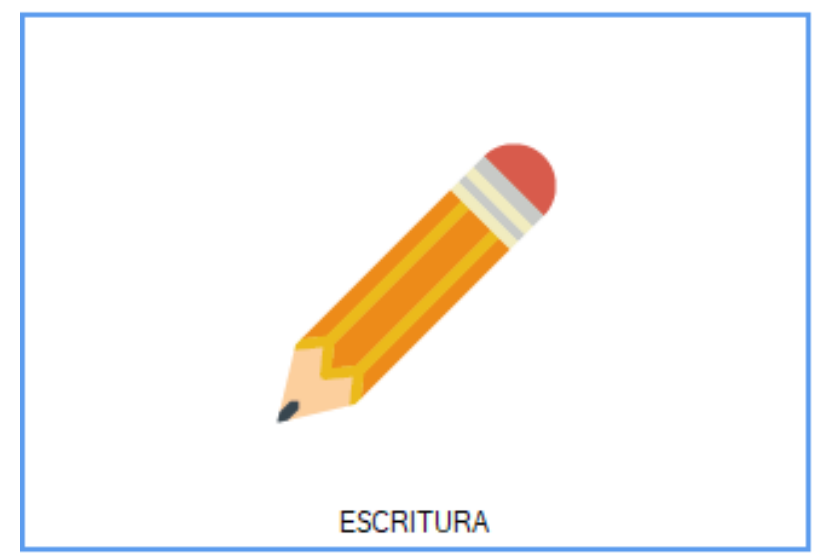

Figura 11 Módulo ESCRITURA

Fuente: Elaboración propia

En este módulo por medio de las imágenes se le solicita al alumno que identifique las diferentes vocales. En alumnos con limitación física severa el docente señalará las diferentes letras y dará al niño opciones de manera verbal para que él responda sí o no. Por ejemplo: ¿esta letra es una vocal.?

ISSN-2523-2452

ECORFAN $^{\circledR}$ Todos los derechos reservados
En la Figura 12 Se muestra el módulo de LECTURA donde el niño lee palabras, frases, comprende frases y textos.

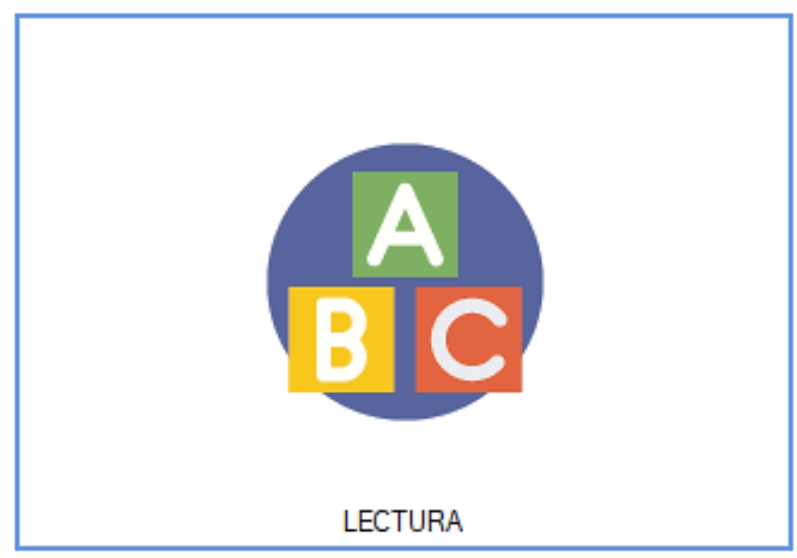

Figura 12 Módulo LECTURA

Fuente: Elaboración propia

Por medio de la opción de LECTURA el alumno leerá palabras, frases o textos. En casos de discapacidad física severa el docente señalará una palabra y dará opciones ¿aquí dice...?, para que responda sí o no.

La demostración de las actividades a los alumnos es de agrado por el simple hecho de interactuar con un dispositivo además de que las imágenes presentadas en las actividades son reales, porque se adapta a su vida diaria con la intención de que el alumno con discapacidad reconozca y se integre al contexto, por lo tanto, estas actividades resultan ser significativas para los alumnos.

Por otro lado, el software interactivo también contiene el módulo de EVALUACIÓN beneficiando la parte operativa-administrativa del docente. En la Figura 13 Se muestra la opción de evaluación mediante la automatización del formato de respuesta.

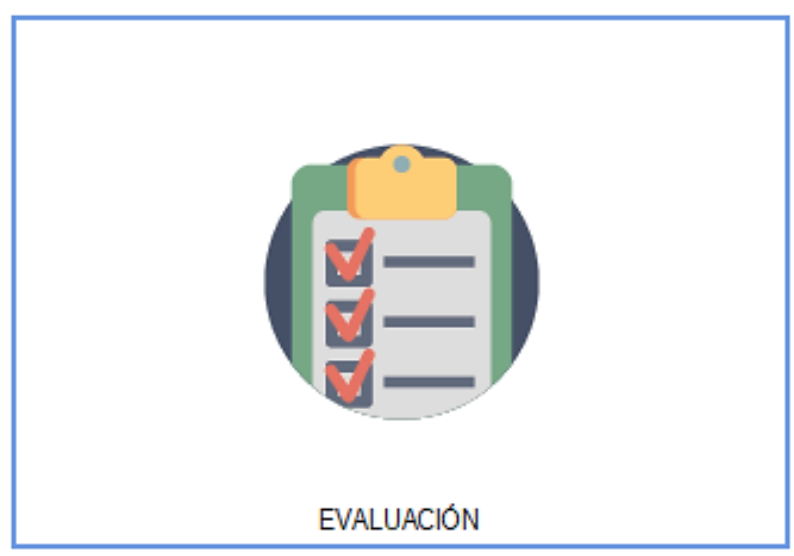

Figura 13 Módulo de EVALUACIÓN Fuente: Elaboración propia

VÁSQUEZ-GAMBOA, Saira Antonieta, GARCÍA-ORTEGA, Irene y RODRÍGUEZ-RAMÍREZ, Felipe. Análisis de los efectos de la implementación de un software interactivo para la inclusión social de personas con discapacidad y su beneficio en niños del centro de atención múltiple (CAM). Revista de Educación Básica. 2020 
La integración de este módulo en el software interactivo es una ventaja, ya que emite los resultados de manera automática sin que el docente tenga que estar requisitando de manera manual dicho formato que se muestra en la Tabla 1 anteriormente descrita.

Durante la fase de pruebas con la docente encargada y el grupo de alumnos a los que se les ha demostrado el software interactivo se determinó que se realizaran modificaciones al software interactivo que consisten en omitir actividades de módulos específicos así como actividades del módulo de evaluación, debido a que los alumnos por el tipo y grado de discapacidad que posee, ya no es posible llegar a realizar ese tipo de actividades, ya que en algunas ocasiones para realizarlas requieren del apoyo del docente.

Una vez que fue probado el software y modificado se procedió a la instalación definitiva en el Centro de Atención Múltiple para dar inicio a su uso en el inmediato ciclo escolar.

\section{Conclusiones}

El software interactivo es una herramienta útil porque apoya al proceso de enseñanzaaprendizaje, en los alumnos y docentes produjo un efecto positivo, en los alumnos siendo este una novedad en la presentación de las actividades mostrando una mejor facilidad de conocer colores, formas, números y sonidos promoviendo su participación, permitiéndoles de manera significativa enriquecer sus conocimientos. La aplicación del software interactivo permite tener control, seguimiento, evaluación y control del proceso de aprendizaje del alumno. En el docente simplifica la aplicación de actividades y de evaluación.

\section{Sugerencias}

Se recomienda que cada módulo se trabaje en diferentes momentos en el CAM o con la familia ya que algunos casos requieren más apoyo, así como también que se respete el ritmo del aprendizaje de los alumnos. También se sugiere que el Centro de Atención Múltiple Gabriela Brimmer continué apoyando este tipo de proyectos que los beneficia y les reduce el tiempo en las actividades.

\section{Agradecimientos}

Se externa el agradecimiento a las siguientes instancias que hicieron posible la realización del proyecto: "Análisis de los efectos de la implementación de un software interactivo para la inclusión social de personas con discapacidad y su beneficio en niños del centro de atención múltiple (CAM) consecuencia del Software interactivo para la inclusión social de personas con discapacidad DISCAP".

- Al Tecnológico Nacional de México por el financiamiento otorgado para el desarrollo del proyecto.

- A los directivos en especial a la directora del Instituto Tecnológico de Tehuacán M.E. Yeyetzín Sandoval González, por todo su apoyo.

- A la directora del Centro de Atención Múltiple Gabriela Brimmer Mtra. Arisbet Paola Méndez Sánchez.

- A la Mtra. L. Ft. Guadalupe Domínguez Gallardo por su colaboración y tiempo.

- A los alumnos que participaron y colaboraron con la realización del proyecto:

\section{- Kristoffer Sosa Espinoza y}

- A los alumnos del Centro de Atención Múltiple CAM Gabriela Brimmer.

\section{Referencias}

Alarcón, P. P., Alarcón, P. J., Mario, V. -g., \& Rosas, C. P. (junio de 2017). Uso de software interactivo en el aprendizaje de la matemática básica. Obtenido de Revista Atlante: Cuadernos de Educación y Desarrollo: http://www.eumed.net/rev/atlante/2017/06/soft ware-interactivo-matematica.html

Alarcón, P. P., Baldeón, S. G., \& Alarcón, P. G. (junio de 2017). Uso de software interactivo en el aprendizaje de la asignatura de estudios sociales. Obtenido de Revista Atlante: cuadernos de Educación y Desarrollo: http://www.eumed.net/rev/atlante/2017/06/soft ware-interactivo-educacion.html 
Brogna, M. P., \& Lic. en Psic. Guadalupe Serrano Delgado, D. E. (2006). Modelo de valoració de habilidades adaptativas para personas con paralisis cerebral y otras discapacidades. México, México.

ENVERA. (s.f.). Habilidades adaptativas en personas con discapacidad intelectual. Obtenido de Asociación de empleados de Iberia padres de personas con discapacidad intelectual: https://grupoenvera.org/sincategoria/habilidades-adaptativas-en-personascon-discapacidad-intelectual/

González-Albo, J. G. (s.f.). Software de comunicación para personal con parálisis cerebral. Obtenido de https://eprints.ucm.es/39887/1/Software\%20de $\% 20$ comunicaci\%C3\%B3n\%20para\%20person as\%20con\%20par\%C3\%A1lisis\%20cerebral\%2 0-\%20Memoria.pdf

Gubernamental, A. N. (s.f). SOLCA. Obtenido de http://solca.aig.gob.pa

Organización Mundial de la Salud. (s.f.). Obtenido de https://www.who.int

Pública, S. d. (2017). Modelo educativo: Equidad e inclusión. Obtenido de http://www.sems.gob.mx

teletón, P. a. (03 de 2011). Boletín mensual programa autismo teletón. Obtenido de https://www.educacionespecial.sep.gob.mx 